Kasper, "Gnundlinien einer Theologie der Geschichte*, TheolQuarialschrift, 144 (1964), 129-169.

16. Sobre todo en De L'Integration-Aspects d'une Theologie de L'Histoire, Brujas, Desclée de Brouwer, 1970, por ejemplo, p. 185.

17. Como podria fundarse en la fe cristiana una esperanza de alcance universal, en el contexto de crisis de la idea de historia universal, es actualmen. te objeto de activa reflexión teológica. Me he ocupado de ello en Escatología I, op. cit., p. 137-163.

18. Puede consultarse sobre el tema a W. Pannenberg, "The Doctrine of Creation and Modern Scien. ces, Zygon, 23 (1988), 3-21 y a R.J. Russell, "Contingency in Physics and Cosmology $\rtimes_{2}$ ibfd. 23-43,

\title{
La reconstrucción estética de la historia del trabajador (Un diálogo casi posible entre Jünger y Weiss)
}

\author{
JOSÉ LUIS MOLINUEVO \\ Universidad de Salamanca
}

Se exponen dos modalidades de reconstrucción estética de la historia, entretejidas con los avatares de un programa romántico para el que la libertad sólo es posible en la belleza y la tarea del Arte consiste en la edificación de una nueva sociedad ético-política. El diálogo entre ambos autores, de talantes tan diversos, es po-

Pero ¿acaso no debiera yo hacer de la libertad que me concedéis un uso mejor que el de encaminar vutestra atención hacia el campo de las bellas artes? ¿No es por lo menos extemporáneo andar ahora buscando un código del mundo estético, cuando los asuntos del mundo moral ofrecen un interés mucho más próximo y el espíritu filosófico de investigación es requerido $\tan$ insistentemente por los acontecimiento a ocuparse en la obra de arte más perfecta que cabe: el establecimiento de una verdadera libertad política? [...] Si resisto a la tentación y antepongo la belleza a la libertad, creo que puedo hallar disculpa, no sólo en mi afición personal, sino en los principios que justifican esa preferencia. Espero persuadiros de que esa materia no es tan ajena a las necesidades como al gusto del siglo; y aun más: que para resolver en la experiencia el problema político, se precisa tomar el camino de lo estético, porque a la libertad se llega por la belleza. sible desde las actuales experiencias narrativas como experiencias históricas. Su prolongación (no realizada aqui) mostraría algunos límites de las estéticas conternporáneas de la resistencia, los supuestos de esos discursos históricos, así como el ethos que subyace a la vacilante pérdida de la normatividad ética.

\section{El quiebro de la quiebra de un programa romántico}

El envite cstético de Schiller es la invitación a salir de una perplejidad histórica en un dialogo instaurador del espacio de juego social que modere la embestida. El diálogo requiere una clarificación previa de los interlocutores interesados que posibilite los niveles del mismo. Lo que le preocupa a Schiller es la solución del enigma de su tiempo: estamos en una época ilustrada, $y, \sin$ embargo, seguimos en la barbarie política y moral. Una época cuya realidad es la contradicción de sus ideales es una época enferma. ¿Más dosis de cultura? Schiller todavía confía en que los umanantiales de culturas lleguen a limpiar la "podredumbre política". Pero ¿qué es 
lo que hay que cultivar y cómo en el hombre? Su respuesta se revela como una de las figuras de la conciencia herida de la modernidad: el kantiano uatrévete a saber» se matiza ahora con el «atrévete a sentir». No se trata ni de acumular conocimientos, ni de emprender una reforma de las facultades, ni tampoco del ejercicio de una razón "natural» que en sus instancias críticas va contra la naturaleza misma. Schiller cree que la reforma político-moral de una sociedad pasa por una educación estética del hombre, y que, de ese modo, se le da lo que necesita, no lo que aplaude. Esto es precisamente lo que configura su intento como una estética de la resistencia: acto tcórico de resistencia que se vuelve práctico en el cultivo de una nueva sensibilidad. Acto por el que pide disculpas, pues conlleva la osadía de romper el velo del misterio de la belleza, haciendo transparente el sentimiento estético mediante una conceptualidad que se sabe de antemano inadecuada por aproximativa y encubridora. Acto que no significa una huida frivola ante los problemas del presente, sino la única forma de pensarlos y encaminar hacia una solución de los mismos. No es una acción política inmediata, pues tiene la convicción de que no se puede cambiar el Estado si no se cambia al hombre que vio en êl su necesidad, y que ahora le reconoce como enemigo al perpetuarse como fin. Un hombre que en Schiller vive la trágica escisión entre sus aspiraciones de humanidad y el precio ilustrado que ha pagado por acercarse a ese ideal como individuo. Por eso no renuncia a presentar su propuesta como fruto de una afición personal, pero con la esperanza de que, al mismo tiempo, tenga un valor metódico en la retórica persuasiva del diálogo entre los que se sienten urgidos por las miserias y la perplejidad del siglo.
El wartista político" de Schiller es aquel que se niega a asumir los presupuestos éticas y las consecuencias politicas de la einsociable sociabilidad kantiana". Por el contrario, afirma que sólo la belleza puede otorgar al hombre un carácter sociable, lejos de la ciega necesidad natural o de las estrategias de poder de la astucia de la razón, que vienen a ser lo mismo. Porque - y es la forma en que este romanticismo recibe a Kant- la herencia kantiana no es la derivada de los usos teorético o práctico de la razón, sino de aquello que los hace posibles: la libertad. Ahora bien, la libertad y el ámbito en que se da no es exclusivamente el moral, sino más bien otro en que este queda englobado: el estético. El Arte es para Schiller el verdadero hijo de la libertad, y es a él a quien está encomendada su realización. $Y$ porque sólo puede desarrollarla en sociedad, por eso, la obra de arte más perfecta consiste en la construcción (Bau) de la libertad política. Una libertad cuyas condiciones de posibilidad no son numca competencia del Estado, ni tampoco de su regulación. Porque el Estado sólo respetará al individuo si éste se respeta a sí mismo. $Y$ es de esta falta de respeto de lo que adolece para Schiller buena parte de la cultura ilustrada y sus teorías del Estado. Falta grave si se ticne en cuenta que la máxima aspiración del individuo es la de vivir en armonía consigo mismo en sociedad, para lo cual el Estado debe ser una necesidad transitoria cuyo destino (en clave fichteana) es el de hacerse en un futuro prescindible.

El «artista político» tiene como materia plástica el hombre moral lleno de tensiones, una materia delicada y explosiva. Su tarea consiste, dice Schiller, en armonizar las facultades, los impulsos, los estadios, las determinaciones humanas, en mediar entre las exigencias de la 
naturaleza y el espíritu. Nunca en sacrificar el individuo a un ideal, ni siquiera el de la dignidad humana, pues ninguna teoría del progreso justifica la

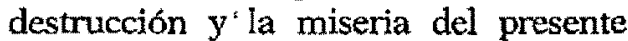
por la construcción de un futuro mejor. O como dice en una de sus frases inspiradas, que no se debe sacrificar al hombre por respeto a la dignidad del hombre. En definitiva, que el carácter regulativo del ideal de la humanidad no debe convertirse en sustitutivo del individuo.

Su propuesta del «impulso de juego» como detención de kel tiempo en el tiempo" rompe con el esquema historicista de un progreso cuantitativo y cualitativo, y también con el uárido concepto del deber" kantiano que le haría posible. Su objeto es crear una afigura viva" (lebende Gestalt), es decir, la belleza. Pero una belleza que, para que sea viva, es necesario que incorpore lo sensible, el goce, la gracia, la apariencia, o, brevemente ( $y$ en una anticipación del proustismo de Benjamin), que incluya la felicidad y, más aún, que engendre un asentido deportivos de la vida (Ortega), opuesto al estrecho de trabajo. El «alma bella» de Schiller es aquella cuya moralidad no está en la acción, sino en el ser, en un particular ethos, que es el instinto de la moralidad en la belleza. Y de este modo es moral porque es verdaderamente libre, porque no sacrifica primero a la naturaleza sensible para obligarla después a participar en el goce insensato de su derrota. La educación estética en Schiller consiste en forjar una nobleza de carácter que no haga necesario tomar decisiones sublimes.

Este programa romántico schilleriano tiene diversas modulaciones epocales. $\mathrm{El}$ ideal de la belleza es una construcción de la razón que unifica los opuestos fragmentados y enfrentados por el discurso del entendimiento y la reflexión. Pero en cualquier caso se trata de una unidad estética, distinta a los procesos de unificación violentos que van a conocer otras formas de idealismo. En «El programa sistemático más antiguo del idealismo alemán» se precisa: «Estoy ahora convencido de que el acto supremo de la razón, al abarcar todas las ideas, es un acto estético, y que la verdad y la bondad se ven hermanadas solo en la bellezan. ${ }^{2}$ Ese acto estético consiste en una tarea de sensibilización que transforma las ideas en ideas estéticas, es decir, mitológicas, creando una mitología de la razón, una nueva forma de religión sensible que unirá al pueblo y a la filosofía, racionalizando lo irracional, en la realización de la libertad. La necesidad de construir esa nueva mitología se pone también de manifiesto en Schlegel, rejuveneciendo la antigua, pero remediando sus ingenuas insuficiencias con la máxina artificiosidad del espiritu en la naturaleza: crear la belleza en el caos haciendo que surja un mundo armónico. ${ }^{3}$ Los múltiples juegos del arte no son sino la mímesis de los infinitos juegos del mundo, por lo que toda belleza es alegoría. Novalis en Los discípulos en Sais cifra la actividad del poeta precisamente en la instauración de ese juego del mundo por el que el hombre está en su casa y se siente hombre en la hospitalidad del hogar. El cuerpo nos introduce en una comunidad de naturaleza en la que todo es cuerpo y espíritu, tiene una historia, una historia natural, que es la contada en el relato poético.

$$
\text { *** }
$$

El programa estético romántico aquí sucintamente descrito se resume en una propuesta basada en una convicción generacional: la belleza nos hará libres. Implica una determinada concepción emancipatoria de la belleza y de la libertad fruto de la revisión de los ideales 
modernos e ilustrados. A este programa han sucedido otros dentro del romanticismo, que unas veces rompen formalmente con él. y otras en confusa amalgama dan origeni a las distintas esteticas fenomenologicas del siglo $\mathrm{xx}$. Es en este contexto donde tiene lugar la quiebra y los quiebros de ese programa, su aparente defunción y el resurgir adaptándose a los nuevos tiempos. Mostrar que la quiebra es un quiebro es el objetivo que se persigue al poner en diálogo narrativo a dos autores y a dos obras de talantes bien distintos. El trabajador de Jünger, y la primera parte de la Estética de la resistencia de Peter Weiss. ${ }^{4}$

Una de las tesis centrales de la obra de Jünger es que este programa moderno y romántico ha quedado herido de muerte en la Primera Guerra Mundial y ya no tiene vigencia. A partir de ese momento el Arte no tiene relación ni con la libertad ni con la belleza como valores absolutos. Porque eran valores de un sujeto que también ha muerto: el sujeto burgués. Lo que queda de ese arte es el museo, el almacén de la belleza ajada y marchita. No tiene capacidad creadora porque su época ha pasado ya y los museos son alos últimos oasis de la seguridad burguesay. Hacer hoy ese tipo de arte significa insconsciencia, huida nostálgica o aprovechamiento de la miseria. El Arte (Jünger globaliza en 1932) que hoy se hace no tiene nada que ver con lo que está pasando. Y lo que pasa es que ha comenzado una nueva era, la era del trabajador, que no es la del sujeto moderno.

El éxito histónico de la obra de Jünger radicaria en haber sabido denumciar el falso radicalismo burgués de los lenguajes estéticos antiburgueses de la época de Weimar, en hacer patentes las contradicciones internas de aquellos que al apoyar el movimiento obrero, sin embargo, no lo eran. Pudo subrayar las aporías insolubles de las vanguardias por el conoci- miento directo de sus medios expresivos, $y$, también, por haberse apropiado de ellos en sus trabajos de la misma época. Ha destruido el mito cultural de los años veinte en una de sus versiones, $y$, por extensión, su rebrote de los años sesenta en una generación huérfana de tradiciones por el fascismo, que posteriormente busca, como Weiss, las razones del fracaso. Ha sabido explicar por qué los que hicieron la revolución proletaria, y sus acompañantes, marcharon después bajo la cruz gamada, y marcharán luego bajo otros símbolos parecidos, estéticamente más presentables. Y sabe explicar ahora, en la emboscadura, cómo se puede conciliar lo inevitable con un nuevo orden que es más viejo que el tiempo mismo. En ese sentido su obra es un ejercicio de lucidez irritante teniendo en cuenta, como el mismo ha manifestado en otra ocasión, que la verdad no siempre cae del lado que más agrada.

Por el contrario, la obra de Weiss es el camino tortuoso y torturado de las posibilidades del programa romántico antes descrito. Significa volver a mirar los acontecimientos decisivos de los años treinta desde la óptica de los vencidos, en la que se reconocen las huellas de Benjamin y la Teoría Crítica. Su título tiene un doble significado: la particular estética de la resistencia del autor plasmada en un libro, una obra literaria. Esto implica una distancia, ya que se nos presenta el paradigma de un héroe, una y otra vez fracasado en la acción directa, como hijo de trabajadores militantes, y luego como auxiliar sanitario en una unidad médica de retaguardia durante la Guerra Civil española, pero vista desde lejos, desde la memoria topológica que iguala los tiempos y los espacios. Al final de ese camino la decisión de narrar, de contar de diferente manera lo visto, aquello que no sale en los libros de historia, se afirma como 
un acto de resistencia. Para ello acude Weiss a algo que se esconde siempre detrás de la historia de los hechos vividos, a la protohistoria. De lo visible, en esta época, que es de la información y la propaganda, a lo invisible, a su sustrato intemporal. Dar cuenta del presente significa reescribir la historia, revisar los mitos, instaurar tradiciones creando una nueva mitología. Enfocadas así, el contraste entre estas dos obras, aparentemente tan dispares, constituye una genealogía del presente en el que conviven desde la tensionalidad del programa romántico: la experiencia histơrica se ha convertido en experiencia narrativa.

Weis muestra las contradicciones que desgarran a los hijos de los trabajadores cuando, después de constatar el fracaso de la lucha patema en la acción directa, quieren acceder a la cultura para comprender lo que pasa, recuperar su identidad y transformarla en un instrumento de lucha política. La cultura es un bien del que han sido despojados, pero que han contribuido a crear, y al que se les impide el acceso como una forma más de dominación. La contradicción se pone de manifiesto $y$ se hace insostenible cuando, tras muchos sacrificios, se logra adquirir esa cultura, y el arte y la belleza pierden su inocencia abstracta y neutral revelándose como participes y cómplices de la injusticia que se quiere combatir. En la posesión de esa cultura el trabajador se siente más desposeído que nunca, incapaz de reconocerse en la identidad que se le ofrece y que le convierte en ajeno a sí mismo y a sus compañeros. Aquella cultura que le salva de la alienación lo hace al precio de convertirte en otro, irreconocible para sí mismo e incómodo y sospechoso para los demás. Lo que iba a permitirle un arraigo le instala en la inhospitalidad del desarraigo.

La reflexión de Weiss toma como punto de referencia las convulsiones de la so- ciedad weimariana, entre las luchas fratricidas de los partidos y el ascenso irresistible del nazismo. La situación histórica en que se plantea este problema es la de Alemania tras la llegada al poder de los nazis, y posteriormente la Guerra $\mathrm{Ci}$ vil española. Toda la obra tiene un ultimo objetivo: tratar de aclararse, explicar, dar razón de un fracaso. Y no hay una respuesta, sino varias, que como diversas imágenes se van fundiendo y se separan en el caleidoscopio de la perplejidad. Es preciso para el autor reescribir la historia de esa época, y ello constituye un acto de resistencia, pero por la misma razón que hay que reescribir el mito de Hercules. Su historia es paralela a la de los héroes socialistas y comumistas: en las luchas fratricidas de los oprimidos ya no se distingue por parte de los actores quién es el héroe y quién es el traidor, porque todas son historias de fracaso. En ese sentido se percibe un contraste entre los planteamientos teóricos de los hijos sobre el trabajador y la cultura, y el sufrimiento de los padres que no entienden cómo pudo venirse todo abajo cuando ellos tenían el poder; cómo los obreros que antes desfilaron bajo la bandera roja son ahora los mismos que lo hacen bajo la cruz gamada. Los análisis vuelven una y otra vez sobre lo mismo en un ritmo monocorde, sólo roto de vez en cuando por los gritos de triunfo del nuevo orden. La primera parte del volumen es una reflexión asfixiante y torturada (no hay puntos y aparte) en espacios cerrados, que por iguales son simultáneos, y que se refleja tambien en la discontinuidad de tiempos hechos contemporáneos. El espacio del trabajador es el mismo, reproducido sin aura en los innumerables tabucos en que sobrevive y muere; su tiempo es un presente indefinido lentamente erosionado por el gusano de la duda.

Su óptica del trabajador está inserta en la lucha de las clases sociales. Pero 
ese contexto se revelará cada vez más estrecho desde el momento en que el protagonista ha accedido a la cultura, lo que le convierte en un ser inevitablemente escindido: la capacidad de ver, de distancia, paralizará su capacidad de acción y le hará crítico respecto a la de los otros. El programa romántico de la realización de la libertad por medio de la belleza se ve traicionado tanto en su desarrollo teórico, como en la salida voluntarista de la acción que todo lo asume y disculpa. Sólo queda la interiorización del mismo bajo la forma de la narratividad, de la reescritura, que asume lúcidamente su precariedad y transitoriedad frente a lo real que discurre por otros cauces. La nueva figura del trabajador saldrá de las cenizas del héroe romántico, pero ya no tiene nada que ver con la antigua lucha de clases.

\section{La cultura del burgués y la cultura del trabajador}

La obra de Jünger está escrita en la vorágine de los acontecimientos sobre los que reflexiona Weiss, y sin embargo, en las dos hay un elemento de distancia que las hace contemporáneas: el llamado elemento posmoderno. La primera se instala en él desde sus comienzos, en la segunda es la conclusión que da origen a la redacción del libro. La distancia que introduce Jinger es la propia de las estéticas fenomenologicas: se trata de hacer visible algo que está ya ahí, pero de lo que no se ha cobrado conciencia, se trata de hacer visible la figura del trabajador, desfigurada y soterrada en los análisis económicos, éticos, filosóficos y culturales, es decir en la teoría. Sólo en una nueva sensibilidad, desde la estética, se podrá acceder a ella. Con este planteamiento, el libro resulta necesariamente híbrido y transitorio por su mismo intento transitivo, ya que su objetivo es ayudar a crear esa nueva sensibilidad en la que el trabajador hablará desde sí mismo, y no como ahora sobre él, por medio de un lenguaje prestado. Porque, afima Jünger, el problema reside en que el trabajador se ha visto siempre (así se lo han hecho ver) como la contrafigura del burgués. Este es el fondo de la dialéctica de la lucha de clases. $Y$ de ese modo nunca ha podio reconocerse a sí mismo ni cuando pretendía llegar, ni cuando parece que llegaba a conquistar las promesas encerradas en los ideales de la burguesía. Por eso, constata Jünger, el trabajador ha sido siempre una marioneta del burgués, porque sus metas le hacian creer que eran las mismas.

La posibilidad de que el trabajador vea su propia figura sólo tendrá lugar cuando cobre conciencia de que la sociedad burguesa es una sociedad condenada a muerte, de que su época ha pasado ya, de que él es la nueva figura emergente, que no tiene nada que ver con la anterior. Ya no se siente, se piensa y actúa con los valores fundamentales que acuño la burguesía: el programa moderno y romántico, dirá Jünger nietzscheanamente, ha muerto porque ha dejado de ser operativo, de ser un valor para la vida. Lo que ha caido, porque se ha vaciado de sentido, son los dos pilares de la ideología burguesa: la libertad y la seguridad. Una libertad afirmada como valor supremo en el primado de la razón práctica idealista, pero cuya paradoja consiste en la falta del verdadero sentido activo en el individuo, paralizado por una ética de la liberación concebida como autorrepresión o huida romántica. En cualquier caso, la libertad ha sido sentida desde el dolor y el sufrimiento, desde la inadaptación al mundo, más que desde su realización transformadora. Jünger constata, pues, un desfase inicial entre la teoría y la praxis burguesa. De ahí que la forma de actuación preferida del burgués haya 
sido, no la lucha que rompe con un estado de cosas y quiere instaurar uno nuevo, sino el contrato, la negación, obra maestra suya. La sombra de los teóricos burgueses de la revolución, pero negadores de la forma en que ésta se produce, constituye el fondo de las acusaciones de Jünger. Nunca han querido realmente la guerra, que es el único acontecimiento radical que pone a prueba a los hombres, los fragua, y los transforma. Por eso el burgués ha vencido en todas, sin distinción de campos, utilizando como ariete y muñeco al soldado y al trabajador. Les ha imbuido de unos ideales heroicos en los que no creía, para convertirlos en falsos protagonistas de unas acciones que no eran las suyas, y el engaño se ha llevado todavía más lejos en el mito romántico de la revolución que devora a sus hijos. La Gran Guerra ha hermanado en sus tumbas a las dos figuras inconscientes de una nueva era: el Soldado Desconocido y el Trabajador anónimo sacrificado al Capital.

Incapaz del verdadero progreso mediante del cambio, el burgués lo concibe como la rutina dentro de la continuidad. Aunque para mantenerla necesite de la ficción de la ruptura, de la afirmación radical de la libertad individual. Hay una correlación en el análisis de Jünger con el lampedusiano: "todo tiene que cambiar para que todo siga igual». Porque la sociedad burguesa se renueva precisamente en los ataques aparentes contra sí misma propiciados o asumidos por ella misma. Esta estrategia es consecuencia de lo que Jünger denomina su componente afemeninow que se revela en la constante asimilación de los opuestos, en la «insociable sociabilidad humana" de Kant, por ejemplo. Cualquier reclamación es tanto más asimilada cuanto más radicalmente se presenta, es decir, como ejercicio de la libertad individual, acabando sujeta a sus leyes y convertida en inoperante para su mejor realización. Por ello, al burgués le resulta particularmente querida la figura del anarquista, símbolo de la catástrofe útil, o también la masa en una sociedad democrática, donde es objeto de recuento, trato y cambalache por los partidos. En definitiva, que la palabra radical es una palabra burguesa; el concepto de libertad es el resultado del cambio de las relaciones responsables por las relaciones contractuales; el modelo de sociedad burguesa es la ilustrada cosmopolita, donde los errores se atribuyen a fallos de pensamiento, de la teoría, que siempre pueden ser corregidos a lo largo del tiempo con más ilustración, información, moralización, comunicación, diálogo y tratados.

La confusión ha estado garantizada por el análisis ampliamente extendido de que el mismo surgimiento del burgués en la modernidad va unido a la idea de trabajo. Pero no a la del trabajador, observa Jünger, por lo que éste se ha convertido en un muñeco movido por el burgués, estando vestido con un ropaje ideológico que le han hecho creer que era suyo, que él se pertenecía y sus movimientos también. De este modo, cuando el trabajador creía tener conciencia de sí, se engañaba respecto a esa autoconciencia, pues era a través de otros (sus propios lídenes), a través de otro (contra el burgués). El ideal racional y ético del mundo ha coincido con una utopía económica del mundo, común a explotadores y explotados, y la lucha de clases se ha revelado como un concepto burgués de la fase burguesa del trabajador, propia de finales del siglo xxx, el siglo por excelencia del triunfo de la burguesía.

En los dos autores el arte es el medio elegido para hacer visible la nueva figura del trabajador en y más allá de un presente contradictorio. En ambos la forma que toma es el discurso estético de la historia. Se parte de la convicción de que ha 
sido falseada impidiéndole adquirir su autoconciencia. En los dos se escribe desde la frustración de los engañados y de los vencidos, pero con la óptica de los vencedores. Una figura debe ocupar (porque ya ha ocupado sin saberlo) el lugar de la otra. Pero esta reescritura de la historia sobre un texto que ya ha sido escrito se revela como tarea imposible, porque los datos, estén o no falseados, son los únicos que hay. El dilema en que se debate la opción representa el momento crítico de la historiografía del siglo xx: o rellenar las lagunas con nuevos datos recreando el pasado o creandolo de nuevo. En esta última opción se inserta el discurso estético de la historia. Su punto de partida es la constatación de la imposibilidad de expresar la nueva figura tomando como modelo las producciones del arte burgues.s. Su punto final, hasta ahora, la creación del pasado en una nueva mitología.

Los dos autores coinciden en la presentación de la forma en que nos es accesible hoy ese arte: el museo y la reproducción. En las míseras viviendas de los trabajadores, dice Weiss, cuelgan sujetas con chinchetas estampas de obras famosas; aquí la belleza es el adorno necesario sobre un fondo agrietado para crear la breve ilusión de que no estamos en un cubil. El día de fiesta pueden contemplarse los originales en el museo. El museo es de todos, pero ¿de quién es, y qué es lo que hay en el museo? Este es el modo inmediato en que podemos plantearnos hoy la otra cuestión, la del ser, desde su origen y cercanía, de la obra de arte. El modo de acceso une ya dos temas para la consideración, el de la identidad y la propiedad, el de qué es propiamente la obra de arte y su posesión. El museo es la mano anónima que recoge los despojos de otras ruinas. En él la obra de arte ya no es tal al perder su tiempo y espacio propios. Es un despojo de sí misma del que han sido despojados orros. Si es cierto que la obra de arte abre al hombre su mundo histórico en forma de destino (tesis sustentada también por Heidegger), los hijos de los trabajadores que contemplan los restos del friso del Altar a Zeus de Pérgamo en Berlín no pueden por menos de experimentar sentimientos contrapuestos. Poseedores de una cultura, y en ese sentido no «pobres de experiencias", sienten como entendidos, especialistas, incluso posmodernos, la alegría melancólica de la ruina en el fragmento: «Fragmentos quebradizos aún conservaban su expresión con todo detalle permitiendo adivinar su totalidad». Por un momento, la ficción ilustrada y romántica de la obra de arte se les representa como un valor libre que pertenece a todos los que alli han entrado. Pero, hijos de los padres que hicieron la revolución proletaria, pobres de sustento, la inmediata cercanía les hace todavía más patente la distancia. Allí donde antes percibian la armonía en la discordia, la lucha entre los dioses y los titanes, del bien y el mal, ennoblecida por el arte, de modo que el patetismo de la acción quedaba subsumido en la elegancia del gesto, ahora, sólo perciben la crueldad de unos gestos, la gracia en los movimientos que subraya todavía más el sufrimiento del zarpazo, una situación que reproduce la suya y que se resiste a ser embellecida.

La escena mitológica que allí se representaba traducia una historia y conmemoraba una victoria: la de los aristócratas, de los plebeyos descendientes de Alejandro Magno, de los diadocos, sobre el pueblo revuelto y por una vez coaligado. Era también una producción de artistas salidos del pueblo para crear una obra inmortal contra el. Aunque eso no era del todo exacto, ya que carecían de esa conciencia, aislados en su producción, sometidos de buen grado a situaciones de mecenazgo, que les colocaban fuera del 
tiempo. La obra de arte no fue propiedad de quienes la crearon, y sólo indirectamente contaba su historia, y tampoco la de sus descendientes, como se puso de manifiesto en su expolio y traslado, por razones de interés superior, por razones de humanidad. La labor arqueológica continúa así una historia de poder, y los hijos de aquéllos se verán obligados con salarios miserables a desenterrar su tradición: «Ellos, los que aún seguían vivos, perecieron en las estepas, en los desiertos y los pedregales para que las piedras pudierar despertar». En estas circunstancias no pueden sentir la obra de arte como suya, sino como peso, como trabajo. Irá a parar a museos donde la verán otros ojos distintos de los suyos.

Por eso, dice Weiss, no extraña la aparente dejadez e incuria de siglos que es lo que convierte a la obra de arte, antes que estéticamente, fácticamente en fragmento, en ruina. Esas obras están destinadas a ser destruidas no sólo por los elementos y las guerras, sino por los hombres que viven cerca de ellas, pero no las sienten como propias, como morada suya. No es una destrucción intencionada y animosa, porque no toman el fragmento como resto de una totalidad frente a la que rebelarse, sino como ruina, descomposición, detritus del poder, del que se aprovechan para construir su verdadera morada cotidiana. Son traperos, que cobijan su precaria estancia con remiendos de cultura.

En la obra de Peter Weiss se entremezclan las consideraciones trascendentales, ontológicas y sociales sobre el origen de la obra de arte. Pervive la teoria del genio que imita la naturaleza (en este caso la sociedad) en la producción intemporal de modelos; tambiën se encuentran huellas de la obra de arte como exposición de lo infinito en lo finito. Pero su componente social relativiza los postulados de universalidad y comunicabilidad basados en es- tructuras trascendentales. Surge la sospecha de que estas son en realidad estructuras sociales, es decir, que la satisfacción e interés puro de la obra de arte traduce las intenciones $\mathrm{e}$ intereses de una clase social. El orden estético se revelaría así como resultado, expresión y trasposición del orden jurídico.

La dialéctica entre el origen social o trascendental y trascendente de la obra dc arte, su intento de síntesis, va a desembocar en una aporía de la que toma su purto de partida temático la obra de Jünger. En definitiva es el mismo reconido que la "Teoría Estética" de Adorno (de quien depende Weiss): la obra de arte hace inmanente en la belleza artística la trascendencia de la belleza natural; es la epifanía de la trascendencia que se hace autotransparente en el concepto. De este modo la filosofía (metafísica) y la estética se socorren mutuamente: la estética es para la metafísica el puerto de refugio ante sus quebradas expectativas kantianas de infinito, y la metafísica le proporciona en la constelación de conceptos aquella transparencia, aquel conocimiento que de lo contrario la dejaría en el ciego sentimiento. La obra de arte es un producto social que refleja las contradicciones sociales: integración y resistencia. El pesimismo adomiano ante la efectiva capacidad política de transformación social por el arte viene del determinismo de su origen: las obras de arte están enfermas y dañadas, y al igual que la metafísi$\mathrm{ca}$, tiene que ir contra sí mismo en su creación en una incansable dialéctica negativa. Son las contradicciones insolubles de la Teoría Crítica por su origen idealista y romántico.

Weiss recorre este camino presentando una dialéctica que en rigor no se plantearía a los vendaderos trabajadores, sino a aquellos intelectuales que piensan sobre o pretenden representar (neoilustración) los intereses de los trabajadores. Estos 
hablan por boca de los padres en la obra, aquêllos por las inquietudes de los hijos. Como resumen de las reflexiones anteriores, el origen social de la obra de arte desde la perspectiva de la lucha de clases lleva a plantear la pregunta límite; si puede haber belleza en la crueldad y si se puede apreciar la belleza en tiempos de crueldad. La madre de uno de ellos, trabajadora fuera y dentro de casa, «[...] tenia que preguntarse si la carga de sufrimientos con que se pagaba el surgimiento de la obra de arte no debía de conferirle a ésta algo de repulsivo en todos los tiempos», para concluir que "[...] en aquello que es cruel en esencia no puede estar contenida la bellezay.

El planteamiento teórico de los hijos quiere ir más allá de la esfera de los sentimientos concretos y vuelve a considerar la obra de arte como un bien cultural al que en principio no afecta su origen respecto a la forma y el contenido. Si los bienes culturales tienen su origen en la crueldad y en el espolio, es preciso recuperarlos, despojándolos de los privilegios de clase, de forma de posesión, para transformarlos en elemento de lucha política. Son bienes de los que han sido desposeídos, y a los que se les sigue impidiendo el acceso. El trabajador no quiere sino recuperar lo que es suyo. Por eso la actitud de conquista y reivindicación debe tener un sentido acrítico. En este contexto no pueden estar de acuerdo con determinadas tendencias de la epoca que proponen la destrucción del arte, porque es nuevamente la actitud de aquellos que poseen ya y se pueden permitir esos lujos. El nihilismo como historia de la decadencia supone algo que para esa clase resulta inconcebible: que alguna vez se ha sido aristócrata de la cultura y de los valores. Textos como los de Kafka reflejan el malestar de una burguesía de la cultura, y por eso les son totalmente ajenos.
En una primera fase, pues, la tarea de ilustración se entiende como recepción de un cúmulo de conocimientos y sólo después se puede plantear un sentido crítico hacia ellos. En ese sentido, piensan que meter al trabajador el sentido crítico, cuando no tiene nada que criticar, es nuevamente una falacia de dominio. Porque, histónicamente, la osadía en el conocimiento ha sido siempre patrimonio de los señores, apoyados por los primeros filósofos, y de este modo podían aventurarse por nuevos países y no temer a los mitos, patrimonio de los pobres, junto al temor a los dioses.

El problema no estaría, pues, en los medios mismos sino en su capacidad para ser utilizados en la lucha política. Y surge, no tanto en aquellos que trabajosamente han accedido a ellos, sino por la reacción de aquellos a los que se quiere transmitir. Hay textos dramáticos en los que Weiss describe brillantemente esta situación. Los que están agobiados por el trabajo no saben cómo reaccionar a lo que se les ofrece, aunque sea con la mejor intención, y siempre se lleva más el maestro que el imposible aprendiz. Es este, el distanciamiento respecto a su propia clase, la no posible comunicabilidad de ese lenguaje, lo que acaba siendo más preocupante. Por ello, piensan que "todo tiene que ser creado de nuevo".

Se plantea, pues, un problema que les coloca en la tópica situación dialéctica: el conocimiento puede tener un carácter liberador, pero mientras no vayan liberándose de su situación no podrán acceder a ese conocimiento. De este modo, las cuestiones leóricas sobre el origen pasan a un segundo plano. $Y$ se introduce un elemento crítico que quiere hacer el papel de mediación: realizada la apropiación de los bienes culturales viene la tarea de recreación de los mismos, para poder hacerlos comunicables y utilizarlos como instrumento de la lucha política. 
Para ello hay que descubrir lo que de contradictorio tiene el arte: "[...] y si se le despojaba de lo que había en él de contradictorio sólo quedaba un muñón desprovisto de vida». Esta tensionalidad es lo que permanece como intemporal en el arte para el trabajador. $Y$ por eso el arte que se creó al amparo de la diosa del recuerdo, de la memoria, lo sigue conservando. "Protege lo que está contenido en la obra total para nuestro propio reconocimiento." Es el momento en que se inicia un proceso paralelo: una acción, la guerra, que purificará y armonizará esas contradicciones y la rescritura de la historia por medio de esos modelos de acciốn que se encuentran en la mitología. Pronto descubrirá el protagonista que en esa guerra (la Guerra Civil española) él y otros como él, en definitiva, "Todos iban buscando algo, pero huyendo de algow. El mismo proceso que la narración de la Primera Guerra Mundial en Jünger: la acción, concebida todavía al modo romántico, en la que se pone en juego lo elemental fraguará un modo de ser del que habían sido incapaces las contradicciones de la teoría. Pero éstas siguen existiendo, y la Guerra tiene una dinámica propia, ajena a las divagaciones intelectuales. Puesto que se sienten traicionados en las expectativas, ellos también traicionan, aceptando como inevitables aquellas situaciones que antes no hubiera admitido su talante crítico. El modo como van cayendo los amigos, por intrigas que ya no tienen nada de heroicas, no despierta un sentimiento de solidaridad en la injusticia sino la reflexión amarga, y la piedad horrorizada, que en definitiva es ante uno mismo, ante los condenados que se aferran sin contemplaciones a la supervivencia. Agotada la última posibilidad de Acción (esta vez con mayúsculas, pues se trata de la Guerra), nuevamente la huida, esta vez bajo la forma del espectador narrativo.

\section{Reescribir el mito}

Jünger emprende una reescritura del mito cuando intenta buscar referentes de una figura que ya no puede hacerse visible dentro del programa cultural y estético de la modernidad. El trabajador empezará a cobrar conciencia de sí mismo cuando se dé cuenta de que no es en oposición a algo, sino que es algo completamente distinto. Se descubrirá como enemigo a muerte de esta sociedad, pero su autoafirmación no viene por la estrategia del derribo, sino por la imposición de su ser y poder. En la diferencia entre "posición» e «imposición" estriba la distancia que separa a las figuras del burgués y el trabajador, del sujeto modemo y la nueva figura. Jünger establece una línea continua en la historia según la cual la teoría del sujeto ha sido siempre una teoría de la propiedad porque en el fondo se ha creído siempre que la cualidad fundamental y determinante de la excelencia era la económica. La construcción metafísica de la identidad del sujeto modemo se ha concebido como una tarea proyectiva de reapropiación en los sucesivos extrañamientos, y de este modo la teoría del Ser ha ido siempre unida a la del Poder. Nada nuevo, afirma Jünger, porque ya desde la Antigüedad se ha entendido la aspiración a la libertad como aspiración económica, de tal modo que esta ultima se ha visto también como una cuestión de aristocracia y rango espiritual. Su recubrimiento ideológico empieza en las pretendidas antinomias entre materialismo y espiritualismo. Por el contrario, el trabajador sólo ve la libertad dentro de la necesidad, de modo que la libertad significa dominio, pero también servicio. Significa el triunfo de lo elemental, lo no sujeto (frente al ideal burgués) a cálculo y seguridad. Figura poderosa, que Jünger no vacila en asi- 
milarla al Leviatán, pero al igual que en los antiguos ciclos, con la esperanza de que a una fase de destrucción siga otra de quietud y de construcción. Su figura es el guerrero, su medio de actuación la guerra, pero no una guerra defensiva, como la burguesa, sino de ataque, porque ya no se trata de que otra clase social tome el poder (el trabajador no es una clase social), sino de que una figura, la única en este siglo, se imponga cobrando conciencia de sí misma llenando todo el espacio de poder.

Todo gira, pues, en torno a la "figura" (Gestalt), el cómo puede verse hoy esa figura. La dificultad no está sólo en la tentación de verla como contrafigura del burgués, y por tanto en entender esa «imposición" en términos de "posición" burguesa; es decir, de entrar en discursos de legitimación y de fundamentación, cuando lo que se impone se sitúa ya automáticamente más allá de ello. La dificultad estriba también en que, según Jünger, todavía nos movemos inevitablemente en el lenguaje de esa sociedad burguesa en extinción. $Y$ eso hace que el nuevo lenguaje simbolico que se inaugura esté teñido necesariamente de ambigüedad. En definitiva, como dice Jünger, el escenario de este mundo es comparable al que resulta de las catástrofes cósmicas y su correlato simbólico es el de las imágenes desgarradas. Estamos en el entreacto de una obra de teatro: el telón ha caído y en la oscuridad se produce un movimiento confuso y agitado en que se prepara un nuevo escenario y tienen que aparecer nuevos papeles y también nuevos actores. De ahí precisamente la dificultad de "ver" en esa confusión en la que emerge la figura. Porque ésta es un todo, que no puede ser recompuesto en la suma de partes o desde ellas, sino visto descle la totalidad. Es la dificultad de un ver que esté situado más allá del valor que se insinúa en todos los juicios y pro- posiciones del lenguaje, y para la que no sirven ya ni los enfoques científicos, éticos o estéticos. De la misma manera que -insistirá luego Jünger-, lo expuesto, por esa ausencia de connotaciones, no es una teoría en la que pueda ver la anticipación de determinados acontecimientos sociales, políticos o nacionalistas. Lo propio de la figura del trabajador es que "es», y en ese ser, en el dejar que se muestre, se instaura la estética fenomenológica. Pero resulta llamativa la referencia que hace a la tarea del profeta como modelo apropiado para llevar a cabo este cometido. Los profetas profetizan el futuro presente, es decir, que primero tiene que arder la llama para que luego llegue la revelación. No obstante, la referencia de Jünger no deja de ser sintomática, por el antecedente kantiano que evoca. Ciertamente la historia profética remite a la protohistoria, pero en Kant la imagen tenía no sólo un elemento de adivinación, sino también de causalidad: los profetas de Israel podían adivinar el futuro porque ellos eran los causantes de las desgracias que profetizaban al pueblo. El diagnóstico de la decadencia se convierte así en una contribución a la destrucción. Algo, por otra parte, muy nietzscheano, ya que éste nos previene acerca de los críticos incansables de la decadencia que en su madurez desengañada se convierten en fervorosos partidarios de la misma.

La figura del Trabajador es la encamación de lo elemental, y no es casual que para Jünger haya comenzado a hacerse visible en todo su temible poderío precisamente en aquel acontecimiento del siglo XX en que han comenzado a mostrarse esas fuerzas desatadas de lo elemental: la Gran Guerra. A partir de entonces nada de lo que sucede en el presente puede ser interpretado en términos de actualidad o de Historia. Es preciso acudir al ámbito de la protohistoria, del que 
sólo nos da una muestra el mito; a esa historia originaria que se realiza en el tiempo, pero que se sustrae a él, de la misma forma que se hurta a los individuos, pues ellos no son los sujetos. Por eso Jünger se siente incómodo en las posibles referencias culturales que hagan visible la Figura, tanto si se trata del superhombre de Nietzsche, como de la Idea platónica o la mónada leibniziana. Lo más próximo a ella serian los nombres que designan los "protofenómenos" como la "Urpflanze" de Goethe, donde se mezclan libertad y necesidad en grado sumo. Ese es uno de los núcleos del discurso estético de la historia, de una "botánica de lo elemental», de una "botánica teológicas, en el que es maestro Jünger, y que recorte toda su obra.

En este contexto, y su correlato spengleriano de la historia, se inserta su caracterización del trabajador como el "animal que trabaja». Lo que significa una revisión del punto de vista aristotélico, del "animal racional", en la medida en que es así traducido, traicionado y seguido por la modemidad. Pero esa revisión va todavía más lejos: esa "planta originaria" (por seguir con la expresión de Goethe), a la que se asemeja la figura del trabajador está dotada de una wwildere Unschuld», de una inocencia silvestre o salvaje. Esto significa una espontaneidad distinta del concepto tradicional de libertad unido a la ética y que tiene un carácter represivo de lo sensible. Es una espontaneidad que proviene de la necesidad del ser que encarna. Es decir, de la espontaneidad de lo elemental. Se encuentra un antecedente de ello en la filosofia de Schopenhauer: una voluntad ciega de existencia que subyace en su identidad a todos los seres y que sólo es captada cuando se intuye en una conciencia cambiada que aeso eres tư", que kvíctima y verdugo son lo mismos. Del mismo modo la figura del trabajador no puede ser captada en y por las partes, que en cuanto tales no existen, pues lo genuino de ella, su grandeza, consiste en ser una totalidad actuante. No hay, pues, lugar a una ética, porque no existe ni la libertad del ser ni la libertad de la acción. La autonegación schopenhaueriana resulta aquí también ilusoria.

Esa "inocencia silvestre" del trabajador lleva a Jünger a situar el trabajo en un contexto distinto de la tradición judeo-cristiana, de la maldición biblica. Aquí tiene el carácter de un castigo por el atrevimiento de un saber, es decir, por la osadia de un querer poder ser más. El castigo le hace penoso y le reduce a un medio cada vez más especializado para lograr la supervivencia, Con ello, el hombre no solo se siente desarraigado de su origen divino, sino opuesto también a la naturaleza, condenado a una labor de explotación que le convertirá en el paso del tiempo a él mismo en explotado. Por el contrario, el trabajo, tal como lo concibe Jünger «[...] es el tempo de los puños, de los pensamientos y del corazón; trabajo es la vida de día y de noche; trabajo es la ciencia, el amor, el arte, la fe, el culto, la guerra; trabajo es la vibración del átomo y trabajo es la fuerza que mueve las estrellas y los sistemas solares.$^{5}$ En la wera del trabajador", el trabajo lo abarca todo, y todos son trabajadores por el mismo hecho de ser. No es ya la forma en que la naturaleza cobra conciencia en el hombre, sino en la que respira.

El "animal que trabaja» ya no es el uanimal racional». Este es el verdadero rostro revolucionario de la nueva figura. $Y$ significa que el hombre ya no es la medida de todas las cosas. Para Jünger el conservador hoy no es aquel que quiere mantener un orden determinado, sino el que quiere reestablecer la imagen del hombre como medida de todas las cosas. En eso se asemeja al revolucionario. Y por eso todas las revoluciones acaban 
siendo también conservadoras. La auténtica revolución, por el contrario, consiste en ver y dejar ser la nueva figura de lo elemental, que de todas formas se impone. Es decir, se trata de ver al hombre como ser hístórico y ser natural, pero en una historia de la que ya no es su medida. Por eso, el trabajador sólo cobrará conciencia de sí mismo cuando vuelva la espalda al mito y a la historia, medios transitorios y deficientes, que dan ilustración pero no conocimicnto, ni salvación. ${ }^{6}$ No basta la explicación histórica y cultural porque de lo que se trata es de construir tradiciones. Y el trabajador es la tradición de sí mismo. Sólo en sí mismo, en su interior, encontrará lo que es. No en la razón apolínea, que hacía astutamente la historia, sino en las fuerzas telúricoplutónicas de la tierra. Es enemigo de los dioses y semidioses, de Hércules, hijo de Zeus, y hermano de los titanes, de los hijos de Gea. Héncules pasa su existencia luchando contra las fuerzas de lo elemental, pero en sus victorias acaba sucumbiendo a ellas. Reescribir el mito significa mostrar una historia de simulacros, en la que las fuerzas titánicas no fueron realmente aniquiladas y si parece que vuelven a resurgir es porque ahora no hay más remedio que adquirir conciencia de ellas si se quiere entender lo que pasa.

El titanismo del trabajador no le permite ser introducido en la historia de los herroes que luchan por ideales. Es anterior y está más allá de ellos. Parafraseando a Nietzsche se puede decir que Jünger le concibe como "el sentido de la tierra». Es el hijo de Gea, la madre, siempre vieja y siempre joven, a la que piden consejo los dioses, anterior a ellos y que les sobrevivirá. Ella representa una fuerza a la que tienen que someterse incluso los poderes divinos de la luz: la necesidad. Sólo si se habla su lenguaje puede tranformarse su dominio destructor en servicio. El hombre ha abandonado hoy el discurso de la libertad para abandonarse a esas fuerzas desconocidas. Nombrarlas, dice Jünger, es el reto que tenemos por delante. Esta es la tarea del arte, que en él, en sus obras, no es sino el intento de seducir esa necesidad obligándola a generar belleza. La actividad de los titanes puede parecer destructora, pero este no es su designio último para Jünger, como tampoco el del nihilismo correctamente entendido. Simplemente, como Anteo, sacan fuerzas de la tierra cada vez que son golpeados contra ella.

El titanismo del trabajador ilustra la forma mediante la cual se im-pone: la técnica. Frente a los discursos habituales sobre ella, Jünger afirma que no es una invención moderna, una posición del sujeto. Por el contrario, la técnica es algo que no tiene nada que ver con él, lo que despoja de sentido a las posiciones fáusticas o los lamentos neohumanistas: ni aprendiz de brujo ni constructor de paraísos. Es una fuerza superior a los individuos, cuyo núcleo no es técnico, y cuya manifestación es el cambio total, la movilización del mundo. Responde, no a una lógica extrema, racionalista, sino a la otra lógica, la del instinto, gratificante en sí misma. Significa un progreso, pero $\sin$ un telos; más bien se trata de aplicaciones determinadas para lograr estados determinados, no conectados entre sí.

Todo ello configura un modo de vida provisional que se desarrolla en el espacio de paisajes transitorios. Ya no se trata de crear algo duradero, seguro, como ocurría tanto en las obras de los antiguos como de los modernos. Por el contrario, la fase primera de la técnica es necesariamente destructora, pero porque no se habla su lenguaje, el que se expresa en el espacio del trabajo. Si el hombre no habla ese lenguaje perece. Si lo acepta se convierte tanto en sujeto como objeto de la técnica, ya que la aplicación de esa 
fuerza configura tanto los ámbitos mayores como menores de la vida. La técnica no es un poder neutral que pueda ser utilizado en mayor o menor grado, en función de unos $\mathrm{u}$ otros determinados valores. Al oponerse a ella, dice Jüngex, tanto la Iglesia, como el caballero, el tejedor, el chino... ya inturan que arrastraba algo más, que suponía un cambio radical de vida. Ella ha acabado definitivamente con la distinción romántica entre ciudad y campo, con la posibilidad de una relación mimética ingenua entre el hombre $y$ la naturaleza.

Pero si se acepta y se impone el lenguaje de la técnica, entonces, a la fase de destrucción y de planificación (en la que estamos ahora) sucederá la de organización. La constancia del cambio engendrara en su perfección quietud, y la movilización total quedara disuelta. Es la utopía expuesta en sus grandes novelas, en la que el hombre es capaz de combinar la posesión de los más sofisticados medios técnicos con el disfrute de sí mismo y de la naturaleza. Hablar el lenguaje de la técnica significa contribuir a buscar esa nueva representación de la vida en la que el trabajo, lejos de la maldición bíblica, ya no puede ser visto bajo la óptica del castigo y el sufrimiento. El término de este cambio será la "espiritualización de la tierra", la construcción de un "Estado mundial", el paso de la figura del trabajador del poder planetario al orden planetario que cerrará la época de los Estados en lucha. Será un "estado» en el que puedan coexistir otros Estados, pero supondrá una reacomodación de un mapa en el que ahora predomina lo político, diferenciándose de lo etnográfico y lo físico.

Final optimista, que corresponde a la segunda fase del nihilismo, productor de realidades nuevas. Porque, como observa Jünger, la técnica es lo único que se sustrae a la lógica de la decadencia.
Pero, ahora, nos encontramos en esa fase intermedia en la que todavia no se habla ese nuevo lenguaje. El mundo, sus ciudades, muestran una abigarrada y confusa policromía magmática. Están corroídas por una insaciable fiebre e inquietud constructora y destructora. Todos coinciden en que han aparecido nuevas realidades, pero se intenta comprender lo que está sucediendo en clave idealista y romántica. Jünger se pregunta cómo es posible en una época en la que suceden cosas de importancia tan llamativa, y que todavia están por delante se las recubra con un barniz del idealismo más desvaído $\mathrm{y}$ de romanticismo en infusión. La respuesta que da es que no se sabe hacer nada mejor.

El paisaje de la tierra cobra así la forma ambigua del taller y el museo. Este último representa uno de los últimos oasis de la seguridad burguesa. Responde a un afán de fetichismo que carece de fuerza creadora, ya que se orienta cotidianamente por la reproducción, sin participar de lo originario. En definitiva, afinma Jünger, nuestros padres podian ocuparse con lo que creían que tenía un valor en sí: el arte y el conocimiento autónomos. Pero ahora ha desaparecido esa autonomía, y sólo cabe ocuparse con lo que afecta a la totalidad. Por todo ello, concluye, el trabajador no debe participar en lo que ahora se entiende por arte. Debe buscar, más bien, el lenguaje de los símbolos en quietud en el que habla intuitivamente la pura existencia. Esa forma de existencia originaria que se expresa en lo primario con rasgos de gran complejidad: en los moluscos, los insectos, los minerales. En ellos se manifiesta una forma de vida en la que confluye el tiempo de la historia y de la protohistoria.

En esa confluencia de tiempos tiene lugar la reconstrucción estética de la historia del trabajador en Jünger. Se sitúa fuera de los límites de una explica- 
ción histórica que tenga en cuenta la mediación social, económica, cultural o histórica desde el punto de vista empírico. En Weiss lo que el arte tiene de contradictorio proviene de su origen social. $Y$ esa es la razón por la que es rechazado por Jünger, como un ejemplo más, ya sea del trabajador o del burgues, de que refleja los intereses de este último apoyados en la ignorancia de su propia condición por aquél. Pero si no sale de estas contradicciones la obra de arte corre el peligro de disolverse, de anularse. El personaje central de Weiss llega a la conclusión de que la única manera de superarlas es convirtiendo la belleza en acción. ${ }^{7}$ Este es el sentido de su venida a España, en cuyas visperas tienen lugar las reflexiones precedentes.

El paralelismo con el planteamiento jungeriano es patente. Se trataría de la realización del paradigma romántico en su primera fase schilleriana, pero con el ejemplo de Byron que no se cita expresamente: salvemos a Grecia, salvemos a España. La realidad es otra, y la guerra le introduce en una dinámica que ya no es la del individuo. No es enviado al frente sino a retaguardia, a una unidad médica, donde percibe las miserias de la guerra, al igual que antes había pcrcibido la derrota de sus padres: la insuficiencia de medios, los heridos arrojados como despojos, el pensar lejos de la acción que transtoma a los hombres de acción, y que les hace caer en las mismas dudas, las mismas disidencias que trajeron de sus países; la difícil integración en las Brigadas Internacionales entre individualismo y mando; las buenas intenciones que degeneran en la anarquía inoperativa. Porque todos vienen buscando algo, pero huyendo de algo. Nuevamente, la complejidad, el no saber lo que está pasando, el sentimiento de utilización por parte de los que sólo tenían la idea de contener y vencer al enemigo, el fascis- mo; el mismo sentimiento que en Alemania: la revolución devora a sus hijos; el presentimiento de una derrota anunciada allí donde momentáneamente toman el poder los obreros, a causa de las disensiones internas, el bajo nivel de instrucción, la utilización siempre por poderes superiones a ellos.

La necesidad es introyectada pero como derrota, y en esa medida se convierte en un nuevo elemento estético. La revolución siempre devora a sus hijos, los trabajadores, afima Weiss. Pero falta el análisis pertinente, tal como encontramos en Jünger: que nunca fueron ni sujeto ni objeto de la misma. Entonces, y ante ese fracaso, se plantea el autor de otra manera la estética de la resistencia: contar las cosas tal como sucedieron, dar otra visión de la historia. Ya no es actor, o lo es de otra manera, como narrador. En cualquier caso, la decisión está tomada, y en virtud de ella se decide también a tragar en el más puro sentido de la palabra: la retirada de Rusia, la insolidaridad de Francia, las alabanzas a los fascistas en la prensa internacional, los guiños de las potencias a un Franco ya vencedor. Todo ello como ayuda a una Rusia asediada por esas alianzas que se preparan en su contra; la necesidad de sacrificar a la República al nuevo orden internacional. En suma: resistir, sí, pero desde la táctica de un nuevo frente contra el fascismo en la próxima conflagración mundial. Lo que no evita la mala conciencia: «Pensar en ello podía ser una autoilusión y equivalía a una traición a nuestros principios básicos».

Esta voluntad de reescribir la historia conlleva una revisión y reescritura, a su vez, de la mitología que la soporta; forma parte de la tarea de autoaclaración, de autoconciencia, que es en definitiva en lo que consiste. Por ello, uno de los bilos del tejido de la obra de Weiss es la reflexión sobre el papel cambiante que 
juega el mito de Heracles en la explicación del presente. Su historia comienza a contarse desde la óptica trágica del héroe que se rebela contra el expolio del origen. Aquel a quien Zeus había destinado ( $\mathrm{sic}$ ) para ocupar el papel preponderante en el mundo se ve postergado por las maniobras de Hera. La tortuosa historia de Heracles es reapropiada por el pueblo, por los vencidos, como señal de esperanza, encontrando en ella claves para la resistencia. $Y$ de este modo, los diferentes trabajos sobrehumanos a los que se ve sometido para poder ser, tener, no son sino expresiones de esa voluntad de resistencia. El fin trágico de Heracles, la continuación de las guerras y la expoliación no le apartaban de la memoria del pueblo.

Esta es una de las posibles lecturas del mito. Pero ¿cómo se ve ahora, desde la derrota? La carta de uno de los amigos, Heilmann, es reveladora. Heracles había representado para los historiadores el consuelo y la esperanza de los oprimidos. Pero Heilmann lo revisa ahora desde los resultados: no había impedido, sino que con él se habían desatado las guerras, y el poder había seguido dominando; sus actos heroicos eran consecuencia de una inquietud proveniente de su origen divino y humano; luchar contra los monstruos era luchar contra sus propias fantasías, temores... El que después de una muerte en medio de horribles tormentos hubiera vuelta a la morada de los dioses, siendo aceptado por ellos, $\mathrm{y}$ viviendo una existencia apacible, le hacia sospechar. Habia sido fagocitado por los dominadores, ellos habían escrito su historia $\mathrm{y}$ le habian convertido, así, en instrumento suyo, tornando sus aventuras en un heroísmo estéril.
Y todavia más. Las causas de su muerte quedan desprovistas de la grandeza trágica con que nos han sido transmitidas: no fue por la túnica envenenada del centauro Neso, sino por transmisión, vía su mujer ofendida y despechada, de todas las enfermedades venereas que el centauro había coleccionado en sus cornerías. Pero esto no podía ser contado así. $Y$ sin embargo, fue una consecuencia lógica del afán de posesión y no amor que se escondía en el sensualismo de Heracles. "Tras todas sus bravuconadas se ocultaba una profunda deformidad psíquica.» En medio de sus sufrimientos estaba más preocupado por su buen nombre en la posteridad que de ellos mismos. Si todo esto fue ocultado y su imagen ennoblecida por los sucesivos relatos clásicos, es porque habia un interés en ello. A los reparos de Heilmann se unen las descarnadas observaciones de Lindbaeck: las aventuras de los héroes son el preludio de las factorías de comenciantes; la cultura griega es el expolio que enmascara y ennoblece el mito; aquellos que no eran nada por sí mismos y no daban nada de lo que poseían y no les pertenecía tenían que inventarse como regalo de los dioses. Su invención era parte de su inventario. Esta es la conclusión desoladora de otra forma de lucidez, de otro modo de escribir la historia: «El capitalismo surgió de los templos bendecido y consagrado por las frases mágicas y el fuego de los sacrificios. Las más famosas imágenes de los personajes olímpicos nacieron después de la creación de los bancos, desde el comienzo de las especulaciones a amplia escala hasta la actualidad, Atenea y Zeus presiden los consejos de administraciónn, Y sin embargo... "A pesar de todo, continuaba Heilmann, aún no he renunciado a Heracles." 


\title{
NOTAS
}

1. Schiller, $F_{n}$ Ober die asthetische Eriehung des Menschen in einer Reihe von Briefen. Samtiche Werke, vol. V, Munich, Hanser, pp. 571-573; trad. Manuel Garcia Morente, Madrid, Espasa, 1968, pp. 13 y 15.

2. Traducido en Hegel, G.W.F.: Escritos de juventud, Ripalda, J.M. (ed.), Madrid, FCE, 1978. p. 220. Citar esta traducción no significa decidir sobre la autoria compartida y discutida del fragmento.

3. "Pues éste es el comienzo de toda poesía, abolir el funcionamiento y las leyes de la razón que piensa razonablemente, y trasladarnos de nuevo a la bella confusión de la fantasia, al caos original de la naturaleza humana, para el que hasta ahora no he conocido símbolo mas hermoso que el abigarrado hervidero de los dioses antiguos (Schlegel, F.r Rede uber die Mythologie. Traducción de Amaldo J. en Fragmentos para una teoria romantica det arte, Madrid, Tecnos, 1987, p. 203).

4. Junger, E: Der Abeiter, en Samtiche Werke, vol. 8, Stuttgart, Klett-Cotta, 1981. Hay traducción de A. Sánchez Pascual, Barcelona, Tusquets, 1990.
Weiss, P.: Die Asthetik des Widerstands, Fráncfort, 1988. Hay una traducción del primer volumen por J. Adsuard Ortega, Barcelona, Versal, 1987.

5. Trad. cit, pp. 69-70.

6. "All donde el pensarniento retrocede a la historia y al mito como a un medio suave o a nichos sernioscuros, es que no se ha emancipado suficientemente. En las crisis se conjura a los héroes, se muestran las reliquias, pero ya no viene ninguna respuesta de alls (Der Arbeiter (Adnoten), op. cit. p. 354).

7. En la política, el arte de lo posible, no hay Jugar para el sentimentalismo, y también en el arte de lo imposible, que abarca nuestras emociones, nuestra personal percepcion de las formas y nuestro sentido poético, todo tiene que ser puesto bajo el signo de la necesidad. La belleza es acción. En las grandes hazañas descubrimos la armonia. Nuestro paradigma es Esquilo, el dramaturgo que también se armó de los pies a la cabeza para marchar al campo de batalla. Así el drama, la literatura, quedaron unidos para siempre a la autosuperación (trad. cit., pp. 316-317).

\section{La ética mostrada}

\author{
CARLOS GÓMEZ SANCHEZ \\ UNED, Madrid
}

Se ha repetido muchas veces, desde Wittgenstein, que la ética es más para ser mostrada, que no para ser dicha. En realidad, el valor que los ejemplos tienen en la vida moral, había sido ya advertido desde Aristoteles. Buena parte de sus Eticas constituye una impresionante descripción de tipos o modelos que encarnarían diversas virtudes -0 vicios-, por más que hoy estemos muy lejos de compartir sus valoraciones y algunas de ellas - precisamente las que Aristóteles colocó en la cima de la vida moralnos puedan parecer, por decirlo con MacIntyre, "aterradoras". Independientemente del contenido de las imágenes que sobre cada uno hayan actuado como catalizadores de su vida moral, si repasamos ésta no nos será difícil descubrir el valor persuasivo que determinadas vidas ejemplares han ejercido sobre cada uno de nosotros. Al parecer Wittgenstein -cuya propia vida tiene mucho de ejemplar - cuando trataba de moral gustaba de comentar algunos «ejemplos» que hicieran reflexionar y tuvieran la fuerza persuasiva de la que la ética, si se quiere aproximar a la zona de sentimientos cálidos, que para ella reclama Aranguren, ha de verse acompañada. Modelos y ejemplos que tienen tanto más valor, cuanto menos impeca- 